\title{
BLENDAS DE CARBOXIMETILCELULOSE E PECTINA DE BAIXA METOXILAÇÃO PARA OBTENÇÃO DE FILMES
}

\author{
$\underline{\text { Juli Barbosa Silva }}{ }^{1}$; Geany Peruch Camilloto ${ }^{2}$ \\ 1. Bolsista PIBIC/CNPq, Graduando em Engenharia de Alimentos, Universidade Estadual de Feira de Santana, e- \\ mail: ilujbarbosa@hotmail.com \\ 2. Orientador, Departamento de Tecnologia, Universidade Estadual de Feira de Santana, e-mail: \\ geanyperuch@yahoo.com.br
}

PALAVRAS-CHAVE: polímeros; blenda; biopolímeros.

\section{INTRODUÇÃO}

A embalagem desempenha um papel expressivo no setor alimentício devido a suas inúmeras aplicações. Filmes e revestimentos a base de polímeros biodegradáveis vem sendo desenvolvidos e pesquisados para utilização como embalagens de alimentos. Dentre os materiais estudados, os biopolímeros naturais, como os polissacarídeos e as proteínas, são os mais promissores, devido ao fato de serem abundantes, renováveis, e capazes de formar uma matriz contínua (GONTARD et al, 1993).

A fim de se obter filmes à base de polímero de fonte renovável, misturas físicas (blendas) de biopolímeros podem ser preparadas. A mistura de polímeros diferentes denomina-se blenda polimérica e possibilita a obtenção de novos materiais com propriedades muitas vezes superiores às dos componentes puros (SIQUEIRA et al, 1993). A principal vantagem das blendas é a simplicidade da preparação e fácil controle das propriedades físicas com a mudança das concentrações dos componentes. Neste contexto, o presente trabalho tem como objetivo obter e caracterizar filmes biopoliméricos a partir da blenda de carboximetilcelulose (CMC) e pectina de baixa metoxilação (PBM).

\section{MATERIAL E MÉTODOS}

Foram elaborados filmes à base de blendas de carboximetilcelulose (CMC) e pectina de baixa metoxilação (PBM). As proporções dos biopolímeros para obtenção das blendas foram obtidas de acordo com o delineamento de mistura binário.

As soluções filmogênicas de CMC e de PBM foram preparadas por meio de agitação da suspensão aquosa do polímero $(5 \% \mathrm{~m} / \mathrm{v})$ contendo $30 \%(\mathrm{~m} / \mathrm{m})$ de glicerol a $1500 \mathrm{rpm}$ por $50 \mathrm{~min}$ e $30 \mathrm{~min}$, respectivamente. Os filmes foram obtidos por processo "casting", as soluções foram misturadas nas proporções indicadas na Tabela 1, espalhadas em placas de vidro e colocadas para secar à temperatura ambiente por $72 \mathrm{~h}$. Os filmes foram realizados em 3 repetições.

Tabela 1 - Proporção dos biopolímeros para produção das blendas

\begin{tabular}{lcc}
\hline Filmes & \% do gel de CMC & \% do gel de PBM \\
\hline A & 0 & 100 \\
B & 25 & 75 \\
C & 50 & 50 \\
D & 75 & 25 \\
E & 100 & 0 \\
\hline
\end{tabular}


A espessura dos filmes foi medida em cinco pontos diferentes de cada filme com o auxílio de um micrômetro da marca Mitutoyo, com precisão de 0,01 mm. As medidas de espessura foram expressas em micrômetros $(\mu \mathrm{m})$.

As propriedades mecânicas dos filmes foram determinadas utilizando-se o Texturômetro TA.XT Plus, com célula de carga de $50 \mathrm{~kg}$, velocidade e distância de separação entre as garras de $5 \mathrm{~mm} \cdot \mathrm{min}^{-1}$ e $50 \mathrm{~mm}$, respectivamente (ASTM, 2009).

Para determinação da permeabilidade ao vapor de água, os filmes foram analisados de acordo com metodologia da ASTM E96 (2000).

A solubilidade dos filmes em água foi avaliada segundo a metodologia de Gontard et al. (1993).

Para análise estatística, utilizou-se o programa STATISTICA versão 7.0. Os modelos obtidos para as respostas experimentais foram avaliados em termos de significância do modelo e dos coeficientes do modelo, e não significância da falta de ajuste, ao nível de 5\% de probabilidade. Os gráficos foram utilizados para analisar o comportamento de cada variável estudada em função das proporções entre os dois polímeros utilizados.

\section{RESULTADOS E DISCUSSÃO}

Os filmes produzidos à base dos polímeros isolados ou da blenda apresentaramse monofásicos, homogêneos, contínuos, sem rachaduras ou poros. A espessura média dos filmes foi de $60,44 \pm 10,70 \mu \mathrm{m}$. O efeito da composição da blenda sobre a espessura dos filmes não foi avaliado em função do processo de produção manual dos mesmos, o que impede o controle de erros experimentais.

O controle da espessura dos filmes é de grande importância porque de acordo com Mahecha (2012) a partir de uma espessura uniforme é possível realizar a comparação dos filmes em relação às propriedades mecânicas, permeabilidade ao vapor d'água, e solubilidade, e propriedades ópticas.

A Equação 2 representa o modelo estatístico, com seu respectivo coeficiente de determinação $\left(\mathrm{R}^{2}\right)$, para a resistência máxima a tração (RMT) dos filmes em função da composição da blenda. A Figura 1 representa o comportamento da RMT dos filmes em função da fração dos componentes poliméricos na blenda.

$$
\mathrm{RMT}=11,87 * \mathrm{PBM}+31,33 * \mathrm{CMC}\left(\mathrm{R}^{2}=0,77\right)
$$

(Equação 2)

Verifica-se que o filme formado apenas por CMC apresentou maior RMT quando comparado ao filme constituído apenas por PBM. Em relação as blendas, os constituintes afetaram a RMT de forma linear, sendo que à medida que a fração de CMC na blenda aumenta maiores são os valores de RMT, enquanto maiores concentrações de PBM na blenda geram filmes com menor RMT.

Segundo Tonhi e Plepis (2002), destacam a importância de blendas compostas por biopolímeros na área de biomateriais, em função da possibilidade de melhorar ou controlar as propriedades mecânicas e biológicas através da interação entre estruturas químicas diferentes.

As propriedades mecânicas das blendas dependem da composição do sistema, da compatibilidade de seus ingredientes, do processamento e da morfologia apresentada 
pelas fases, entre outros fatores. Um dos requisitos para o sucesso de uma blenda para a aplicação final é a homogeneidade da mistura polimérica (VOET e PRATT, 2000).

Figura 1 - Variação da resistência máxima a tração dos filmes em função da concentração de carboximetilcelulose e pectina de baixa metoxilação.

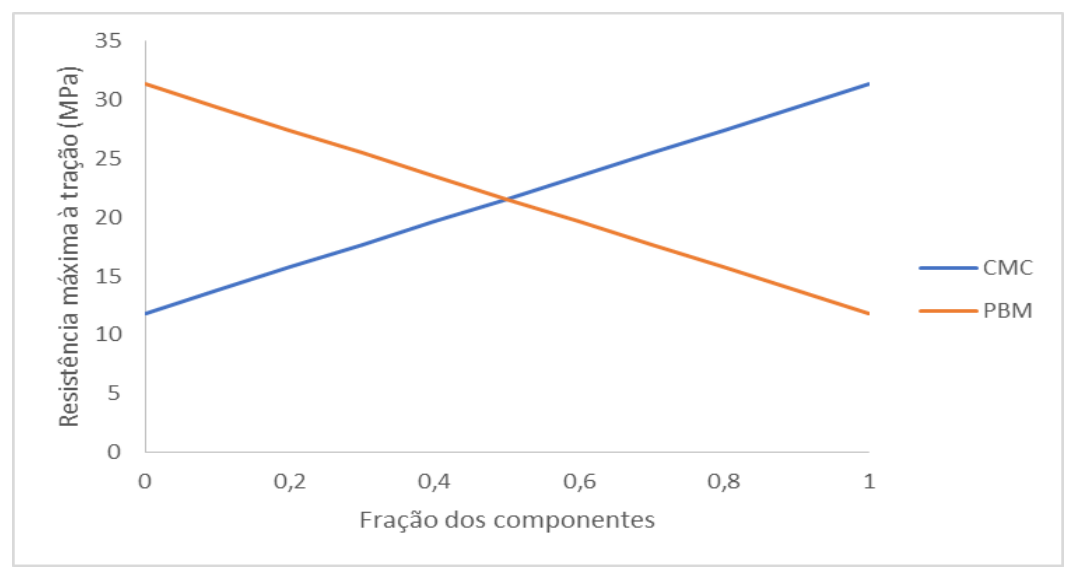

Não foi possível ajustar um modelo de regressão significativo para explicar o efeito da composição da blenda sobre a porcentagem de alongamento na ruptura.

A permeabilidade ao vapor d'água (PVA) foi significativamente afetada composição da blenda. O modelo de regressão ajustado e o comportamento da PVA em função da fração dos constituintes estão apresentados na Equação 3 e Figura 2.

$\mathrm{PVA}=3,48 * \mathrm{PBM}+7,20 * \mathrm{CMC}-5,99 * \mathrm{PBM}^{*} \mathrm{CMC}\left(\mathrm{R}^{2}=0,86\right)$

(Equação 3)

Figura 2: Variação da permeabilidade ao vapor d'água dos filmes em função da concentração da fração dos componentes

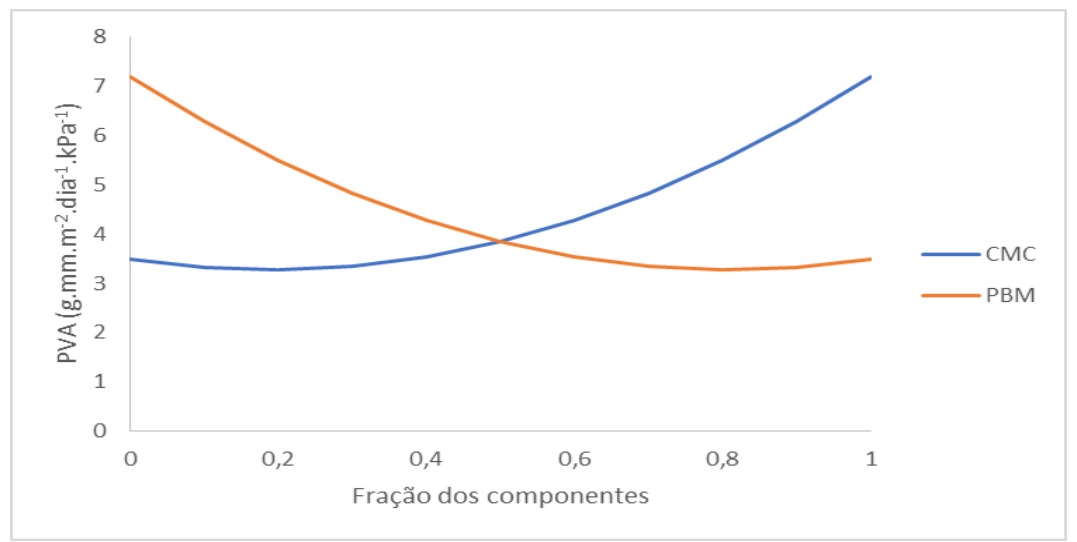

A PVA foi menor para filme de pectina quando comparados ao filme de CMC. Em relação as blendas, os constituintes afetaram a PVA de forma quadrática, sendo que à medida que a fração de PBM na blenda aumenta menores são os valores de PVA, enquanto maiores concentrações de CMC na blenda geram filmes com maior PVA. 
A maior limitação para aplicação de filmes à base de biopolímeros é a solubilidade em água e a alta permeabilidade ao vapor de água, devido a sua hidrofilicidade.

Geralmente, uma elevada solubilidade pode indicar baixa resistência a água pelos filmes. No entanto, a alta solubilidade pode ser uma vantagem para algumas aplicações como em situações em que os filmes serão consumidos com um produto semipronto, que é aquecido antes do consumo (BOURTOOM e CHINNAN, 2008).

Todos os filmes apresentaram-se $100 \%$ solúveis em água, independente da concentração de carboximetilcelulose e pectina BTM, um caráter altamente hidrofílico e prejudicial para aplicação em alimentos ou produtos que necessitem de menor afinidade por água. A estrutura dos polissacarídeos e presença de grupos carboxilatos na composição dos filmes, é um dos fatores que mais afeta a sua solubilidade em água. Porém em outros casos, a solubilidade é desejável e benéfica ao produto revestido, como por exemplo, em produtos prontos para o consumo (PÉREZ-GAGO et al., 1999).

\section{CONCLUSÃO}

As propriedades dos filmes formados pelas blendas são intermediárias àquelas apresentadas pelos polímeros individuais podendo ser controladas variando-se a proporção de carboximetilcelulose e pectina de baixa metoxilação na blenda. Isso evidencia o efeito cooperativo dos polímeros, sendo que blendas com maior quantidade de CMC geram filmes mais resistentes e blendas com maior quantidade de PBM geram filmes com maior barreira ao vapor de água.

\section{REFERÊNCIAS}

ASTM - AMERICAN SOCIETY STANDARD TESTING AND MATERIALS. Standard Test Method for Tensile Properties of Plastics. D 638. Philadelphia: ASTM, 2009.

ASTM - AMERICAN SOCIETY STANDARD TESTING AND MATERIALS. Standard Test Method for Tensile Properties of Plastics. D 638. Philadelphia: ASTM, 2009.

BOURTOOM, T.; CHINNAN, M. S. Preparation and properties of rice starch-chitosan blend biodegradable film. LWT - Food Science and Technology, v. 41, n. 9, p. 16331641, 2008.

GONTARD, N.; GUILBERT, S.; CUQ, J. L. Water and glycerol as plasticizers affect mechanical and water vapor barrier properties of an edible wheat gluten film. Journal of Food Science, vol. 58, n. 1, p. 206-211, 1993.

MAHECHA, M. M. A. Microcompósitos, nanocompósitos e coberturas a base de materiais biodegradáveis obtidos a partir do Biri (Canna indica L.). Tese (Doutorado em Engenharia de Alimentos). Universidade Estadual de Campinas. Campinas: 2012.

PÉREZ-GAGO, M. B.; NADAUD, P.; KROCHTA, J. M. Water Vapor Permeability, Solubility, and Tensile Properties of Heat- denatured versus Native Whey Protein Films. Journal of Food Science, v. 64, n. 6, p. 1034-1037, 1999.

TONHI, E.; PLEPIS, A.M.G. Obtenção e caracterização de blendas de colágenoquitosana. Química nova, v. 25, p. 843-948, 2002.

VOET, D. V., J.; PRATT, C.W. Fundamentos de Bioquímica. Artmed: São Paulo, 2000; 931p. 